\title{
OUTCOMES FROM MESENTERIC-PORTAL AXIS RESECTION DURING PANCREATECTOMY
}

\author{
Resultados da ressecção do eixo mesentérico-portal durante a pancreatectomia
}

Enio Campos AMICO ${ }^{\mathbf{1 , 2}}$, José Roberto ALVES ${ }^{\mathbf{1}, 2}$, Samir Assi JOÃO',

Ricardo Wagner da Costa MOREIRA ${ }^{1}$, José Linhares da SILVA NETO², Joafran Alexandre Costa de MEDEIROS ${ }^{1}$

From the ${ }^{1}$ Hospital Universitário Onofre Lopes da Universidade Federal do Rio Grande do Norte and 2Liga NorteRiograndense contra o Câncer ('Onofre Lopes University Hospital, Federal University of Rio Grande do Norte and 'Liga NorteRiograndense Against Cancer), Natal, RN, Brazil.

HEADINGS - Vascular surgical procedures. Pancreaticoduodenectomy. Pancreatic Neoplasms.

\section{Correspondence:}

Enio Campos Amico,

e-mail:ecamic@uol.com.br

Financial source: none

Conflicts of interest: none

Received for publication: 27/05/2014 Accepted for publication: 21/08/2014

DESCRTORES - Procedimentos cirúrgicos vasculares. Duodenopancreatectomia. Neoplasias pancreáticas.
ABSTRACT - Background: Due to their complexity and risks, mesenteric-portal axis resection and reconstruction during the pancreatectomy procedure were not recommended back in the early nineties. However, as per technical improvements and the reduction in morbidity and mortality rates, they have been routinely indicated in large medical centers. Aim: To show results from cases of patients subjected to mesenteric-portal axis resection during pancreatectomy. Method: Patients subjected to mesenteric-portal axis resection during pancreatectomy were prospectively and consecutively assessed. The procedure was indicated according to anatomical criteria defined by imaging exams or intraoperative assessment. Results: Ten patients, half of them were male, with mean age of 55.7 years (40-76) were included. The most frequent underlying diseases were pancreatic adenocarcinoma and Frantz tumor. The circumferential resection of the portal vein associated with the superior mesenteric vein with splenic vein ligature ( 4 cases $=40 \%$ ) and the primary anastomosis of the vascular stumps ( 5 cases $=50 \%$ ) were, respectively, the most performed types of vascular resection and reconstruction. Surgery time ranged from 480 to 600 minutes (average $=556$ minutes) and postoperative hospitalization time ranged from 9 to 114 days (average $=34.8$ days). Morbidity rate was $60 \%$, and clinical pancreatic fistula (grade B and C) was the most common complication ( 3 cases $=30 \%$ ). Mortality rate was $10 \%$ ( 1 case). Conclusion: Mesenteric-portal axis resection is a valid technical procedure. It should be taken into account after a clinical assessment that included not only the patients' clinical condition but also the technical and anatomical conditions of the mesenteric-portal axis tumor infiltration as well as life expectancy based on the patient's cancer prognosis.

RESUMO-Racional: Devido à complexidade e riscos, a ressecção e reconstrução do eixo mesentéricoportal durante pancreatectomia até o início dos anos noventa não era recomendada. Entretanto, com o aprimoramento técnico e redução da morbimortalidade ela tem sido indicada de forma rotineira nos grandes centros. Objetivo: Demostrar os resultados de uma série de casos submetida à ressecção do eixo mesentérico-portal durante a pancreatectomia. Método: Foram avaliados prospectivamente e consecutivamente pacientes submetidos à ressecção do eixo mesentéricoportal durante pancreatectomias. A indicação do procedimento baseou-se em critérios anatômicos definidos por exames de imagem ou por avaliação intra-operatória. Resultados: Foram incluídos 10 pacientes, metade do sexo masculino, com idade média de 55,7 anos (40-76). As doenças de base mais frequentes foram o adenocarcinoma de pâncreas e o tumor de Frantz. $O$ tipo de ressecção e reconstrução vascular mais realizado foi respectivamente a ressecção circunferencial da veia porta associada à veia mesentérica superior com ligadura da veia esplênica (4 casos $=40 \%$ ) e a anastomose primária dos cotos vasculares ( 5 casos $=50 \%$ ). O tempo operatório variou entre 480 e 600 minutos (média=556 minutos) e o tempo de internação pós-operatória variou de 9 a 114 dias (média=34,8 dias). A morbidade foi de $60 \%$, sendo a fístula pancreática clínica (grau B e C) a complicação mais frequente (3 casos=30\%). A mortalidade foi de $10 \%$ (um caso). Conclusão: A ressecção do eixo mesentérico-portal é artifício técnico válido. Deve ser considerada após consideração que contemple não apenas as condições clínicas dos pacientes, as condições técnicas e anatômicas da infiltração tumoral do eixo mesentérico-portal, mais também, e de forma não menos importante, a expectativa de sobrevida com base no prognóstico oncológico do paciente.

\section{INTRODUCTION}

$\mathrm{T}$ he first resection and reconstruction of part of the mesenteric-portal axis (MPA) during pancreaticoduodenectomy was reported by Moore et al. ${ }^{8}$, in 1951. However, due to its complexity and risks, such procedure was considered as contraindicated ${ }^{6}$ until the early 1990s. Since then, it started being routinely performed, due to the reduction in morbidity and mortality rates achieved by the technical improvement in medical centers where pancreatic resections are performed. In our country, the outcomes from MPA resection are little disclosed.

The current study aims to demonstrate outcomes from patients subjected to MPA resection during pancreatectomy.

\section{METHOD}

This study was approved by the Ethics Committees of Onofre Lopes University Hospital, Federal University of Rio Grande do Norte and Liga Norte-Riograndense Against Cancer, Natal, RN, Brazil. 
Patients who underwent MPA resection during pancreatectomies performed from April 2007 to July 2014 in order to treat pancreatic or peripancreatic diseases were prospectively and consecutively assessed.

MPA resection was indicated to patients with pancreatic tumors according to essentially anatomical criteria defined during preoperative imaging examinations or intraoperative evaluation. Thus, the procedure was indicated in cases in which, in order to completely remove the pancreatic lesion, it was also necessary to resect part of the portal vein, superior mesenteric vein or the splenic vein at the MPA confluence and, in addition, a vascular reconstruction procedure was feasible.

Some technical principles were used: 1 ) the end of the surgical specimen dissection was the appropriate moment for MPA resection and reconstruction, when it was totally free from other anatomical structures; 2) whenever possible, a choice was made for the primary anastomosis with vascular stumps from the MPA itself; 3) 2500 - 5000 UI sodium heparin was intravenously administered before clamping; 4 ) anastomosis was performed by using continuous polypropylene suture $6-0$ (growth factor from 1 to $1.5 \mathrm{~cm}$ was used for anastomosis expansion after unclamping); 5) a vascular graft was used in the longest resections or in those in which the vascular stumps approximation generated stress. Vascular surgeon assistance was requested in order to perform vascular reconstruction in the graft cases.

The remaining technical steps related to pancreatic resection, transitreconstruction, cavitydrainageand postoperative care were described in a previous study ${ }^{1}$. As for the pancreatic fistula diagnosis, it was used the criteria from the International Study Group on Pancreatic Fistula Definition ${ }^{2}$. The diagnosis of bleeding and delayed postoperative gastric emptying was based on definitions proposed by the International Study Group on Pancreatic Surgery ${ }^{13,14}$.

In-hospital mortality was taken under consideration when death occurred within the first 90 postoperative days.

In the second postoperative week, imaging tests (computed tomography or Doppler ultrasound of the abdomen) were routinely requested. Additional tests aiming to assess MPA patency were conducted during the regular follow-up of patients with neoplasia or, when it was not the case, they were required at yearly intervals for the first three years.

\section{RESULT}

Seventy-five pancreatectomies were performed during the study period. Of these, it was necessary to perform MPA resection in 10 cases, which were considered as the study sample. In nine of these patients, the vascular procedure was performed during pancreaticoduodenectomy, whereas, in one of them, central pancreatectomy was the primary performed procedure. Half of the sample consisted of male patients. The average age was 55.7 years (40-76).

As for the underlying disease, pancreatic adenocarcinoma was the most prevalent one among half of the samples (50\%), and the second one was Frantz's tumor which was found in two cases (20\%) (Table 1$)$. Although, as a rule, pancreatic cystadenoma has no indication for surgery, if there is suspicion of mucinous lesion or if the lesion grows - as it was observed in a single patient who attended the current study -, thus the lesion's removal was indicated. The segmental resection was performed in the transverse colon of one of the patients with pancreatic adenocarcinoma, due to local invasion by the tumor.

Most of the patients in the sample ( 7 cases $=70 \%$ ) was subjected to isolated circumferential resection of the portal vein, superior mesenteric vein or of the confluence between them. Tangential resection was performed in the other three cases (30\%). The type of vascular reconstruction was intraoperatively defined depending on the circumferential extent of the tumor's involvement. In most cases, such reconstruction was performed with primary suture of the vascular stumps ( 6 cases $=60 \%$ ) (Figure 1 ).

In two cases (20\%) it was necessary to perform venous grafting (Figure 2) and in two other cases (20\%), the polytetrafluoroethylene prosthesis (Table 1 and Figure 3) was used.

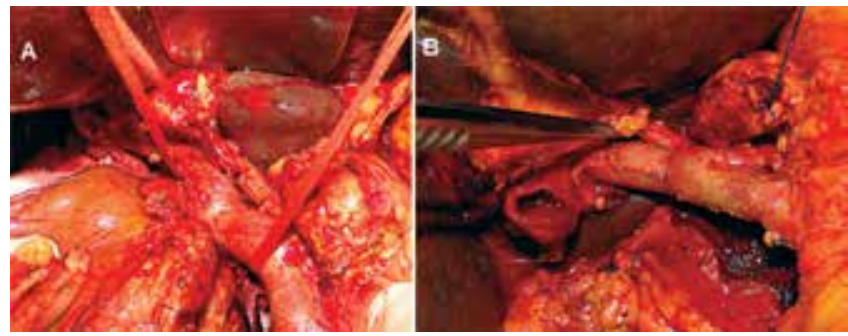

FIGURE 1- Ilustration of pancreaticoduodenectomy after releasing the surgical specimen and of the type of vascular reconstruction after resecting part of the MPA: A) pancreaticoduodenectomy surgical specimens were dissected and released, and attached only by tumor infiltration in the portal vein; B) vascular reconstruction by means of primary suture of the vascular stumps

TABLE 1 - List of diseases, tumor size and technical features related to the MPA reconstruction $(n=10)$

\begin{tabular}{|c|c|c|c|c|c|}
\hline $\mathrm{n}$ & Diseases & Tumor size & $\begin{array}{c}\text { Type of } \\
\text { venous resection }\end{array}$ & $\begin{array}{l}\text { Extent of venous } \\
\text { resection }\end{array}$ & $\begin{array}{l}\text { Type of } \\
\text { reconstruction }\end{array}$ \\
\hline 1 & Pancreatic adenocarcinoma & $4 \mathrm{~cm}$ & $\begin{array}{l}\text { Circumferential resection including PV/ } \\
\text { SMV with ligation of SV }\end{array}$ & $4,0 \mathrm{~cm}$ & $\begin{array}{l}\text { Primary anastomosis of } \\
\text { the vascular stumps }\end{array}$ \\
\hline 2 & Frantz's tumor & $7,0 \mathrm{~cm}$ & $\begin{array}{l}\text { Circumferential resection including PV/ } \\
\text { SMV with ligation of SV }\end{array}$ & $6,0 \mathrm{~cm}$ & Venous graft (with SV) \\
\hline 3 & Papillary adenocarcinoma & $2,3 \mathrm{~cm}$ & Isolated circumferential resection of PV & $2,0 \mathrm{~cm}$ & $\begin{array}{c}\text { Primary anastomosis of } \\
\text { the vascular stumps }\end{array}$ \\
\hline 4 & Pancreatic adenocarcinoma & $3,0 \mathrm{~cm}$ & Tangential resection of SMV & $1,5 \mathrm{~cm}$ & SMV plasty \\
\hline 5 & Pancreatic adenocarcinoma & $5,5 \mathrm{~cm}$ & $\begin{array}{l}\text { Circumferential resection including PV/ } \\
\text { SMV with ligation of SV }\end{array}$ & $4,5 \mathrm{~cm}$ & $\begin{array}{l}\text { Primary anastomosis of } \\
\text { the vascular stumps }\end{array}$ \\
\hline 6 & $\begin{array}{l}\text { Cholangiocarcinoma of the } \\
\text { distal common bile duct }\end{array}$ & $7,5 \mathrm{~cm}$ & $\begin{array}{l}\text { Circumferential resection including PV/ } \\
\text { SMV with ligation of SV }\end{array}$ & $5,0 \mathrm{~cm}$ & Graft with PTFE prosthesis \\
\hline 7 & Pancreatic adenocarcinoma & $1,9 \mathrm{~cm}$ & Isolated circumferential resection of PV & $2,0 \mathrm{~cm}$ & $\begin{array}{l}\text { Primary anastomosis of } \\
\text { the vascular stumps }\end{array}$ \\
\hline 8 & Pancreatic adenocarcinoma & $3,0 \mathrm{~cm}$ & Tangential resection of MPA confluence & $3,0 \mathrm{~cm}$ & Graft with PTFE prosthesis \\
\hline 9 & Serous cystadenoma & $7,0 \mathrm{~cm}$ & $\begin{array}{l}\text { Isolated circumferential resection of } \\
\text { SMV }\end{array}$ & $1,5 \mathrm{~cm}$ & $\begin{array}{l}\text { Primary anastomosis of } \\
\text { the vascular stumps }\end{array}$ \\
\hline 10 & Frantz's tumor & $4,0 \mathrm{~cm}$ & Tangential resection of MPA confluence & $5,0 \mathrm{~cm}$ & Venous graft (with IJV) \\
\hline
\end{tabular}

$\mathrm{n}=$ patient number; $\mathrm{PV}=$ portal vein; $\mathrm{SMV}=$ superior mesenteric vein; $\mathrm{SV}=$ splenic vein; MPA= mesenteric portal axis; $\mathrm{PTFE}=$ polytetrafluoroethylene; $\mathrm{VJI}=$ internal jugular vein 


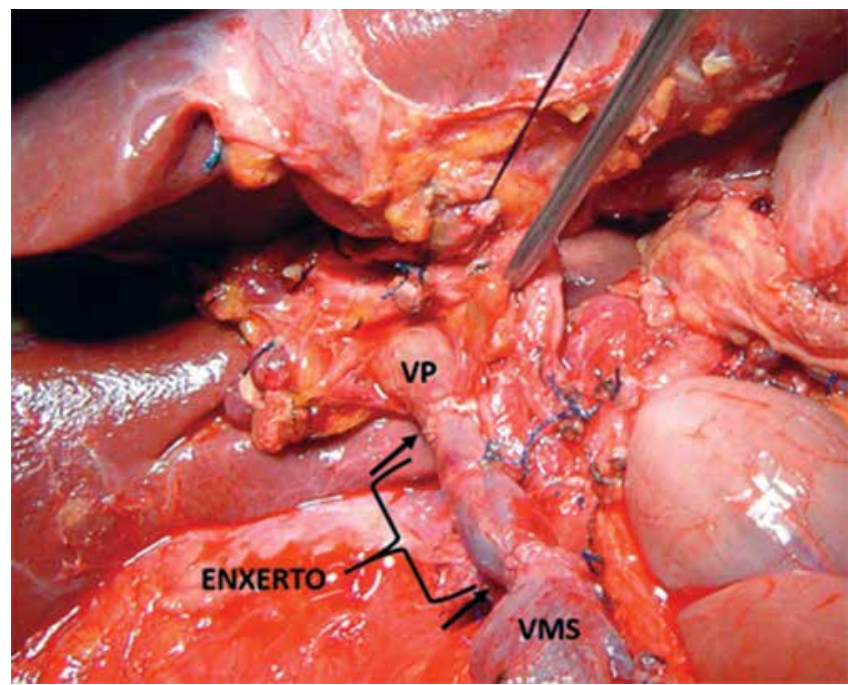

$\mathrm{PV}=$ portal vein; $\mathrm{SMV}=$ superior mesenteric vein

FIGURE 2- Exemplification of vascular reconstruction by means of splenic vein graft

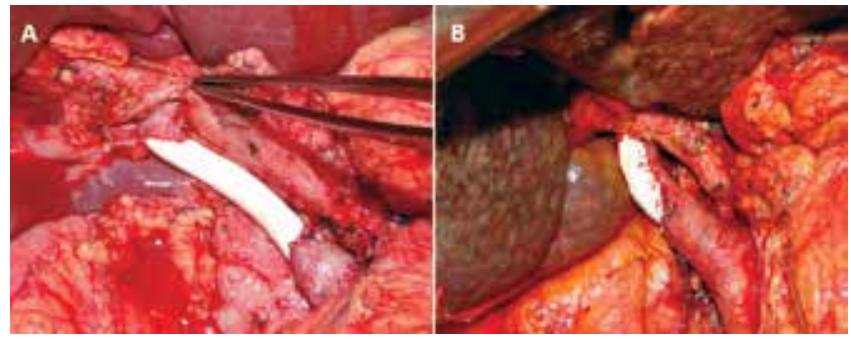

FIGURE 3 - Use of graft with polytetrafluoroethylene vascular prosthesis: A) interposition of the prosthesis between the superior mesenteric vein and the portal vein; B) use of it after isolated tangential resection of the portal vein

The surgery time ranged from 480-600 min (average $=556 \mathrm{~min}$ ) and postoperative hospitalization time ranged from 9-114 days (average $=34.8$ days). Morbidity rate was of $60 \%$. Clinical pancreatic fistula (grades B and C) was found in three cases (30\%). Intraperitoneal bleeding and delayed gastric emptying occurred, respectively, in two (20\%) and one (10\%) of the cases. Biliary fistula and fecal peritonitis were identified in one patient each. The reoperation rate was of $40 \%$, and it happened as a consequence of fecal peritonitis (in the case in which segmental colectomy was performed), intraperitoneal bleeding, biliary fistula, and pancreatic fistula. Mortality rate was of $10 \%$. The only death case occurred on the $12^{\text {th }}$ postoperative day and it due to intraperitoneal bleeding resulting from a splenic vein lesion that led the patient to re-operation. Although the surgeon managed to control the bleeding, the patient developed acute renal failure and coagulopathy.

Anastomosis patency was evaluated in all patients during the postoperative period. On average, two imaging examinations were performed in each patient. Computed tomography of the abdomen with intravenous contrast was the examination performed in nine cases (90\%). In $80 \%$ of these cases, there was MPA patency. In one patient (case 2), there was stenosis on $80 \%$ of the splenic vein graft and the development of collateral veins in the mesentery and stomach was identified four years after the procedure. Stenosis was corrected by means of metallic stent implantation. In another patient (case 8), right portal vein thrombosis was found as a consequence of liver metastasis.

Patients' survival is shown in Table 2. Compatible with advanced stage (IIB) which was observed in $80 \%$ of patients with pancreatic adenocarcinoma, the average survival in this group was of 15 months (4-24). The two patients with Frantz's tumor and the patient with serous cystadenoma remained alive, without disease recurrence and with patent MPA.

TABLE 2 - List of diseases, tumor stage (according to the TNM UICC classification 7th edition) and survival $(n=10)$

\begin{tabular}{|c|c|c|c|}
\hline $\mathrm{n}$ & Disease & Tumor stage & Survival \\
\hline 1 & $\begin{array}{c}\text { Pancreatic } \\
\text { adenocarcinoma }\end{array}$ & T3N1M0 / IIB & 24 months \\
\hline 2 & Frantz's tumor & - & $\begin{array}{l}\text { Free of the disease for } \\
5 \text { years and } 1 \text { month }\end{array}$ \\
\hline 3 & Papillary adenocarcinoma & T3NOMO / IIA & Intraoperative death \\
\hline 4 & $\begin{array}{c}\text { Pancreatic } \\
\text { adenocarcinoma }\end{array}$ & T3N1M0 / IIB & 11 months \\
\hline 5 & $\begin{array}{c}\text { Pancreatic } \\
\text { adenocarcinoma }\end{array}$ & T3N1M0 / IIB & 4 months \\
\hline 6 & $\begin{array}{l}\text { Cholangiocarcinoma of the } \\
\text { distal common bile duct }\end{array}$ & T3N1M0 / IIB & 9 months \\
\hline 7 & $\begin{array}{c}\text { Pancreatic } \\
\text { adenocarcinoma }\end{array}$ & T2NOMO / IB & 23 months \\
\hline 8 & $\begin{array}{c}\text { Pancreatic } \\
\text { adenocarcinoma }\end{array}$ & T3N1M0 / IIB & 13 months \\
\hline 9 & Serous cystadenoma & - & $\begin{array}{l}\text { Free of the disease } \\
\text { for } 8 \text { months }\end{array}$ \\
\hline 10 & Frantz's tumor & - & $\begin{array}{l}\text { Free of the disease } \\
\text { for } 2 \text { months }\end{array}$ \\
\hline
\end{tabular}

\section{DISCUSSION}

There is no doubt that vascular resection and reconstruction are feasible and they allow more radical surgeries in pancreatic tumors involving the vascular elements composing the MPA ${ }^{5}$. Such fact was observed in the current series. The two controversial aspects of this procedure concern its comparison with the pancreaticoduodenectomy, in which vascular resection is not necessary. Would morbimortality and survival be similar in both procedures?

Yuet al. ${ }^{15}$, in a recent meta-analysis, found 22 comparative studies on pancreatectomy with or without vascular resection, thus demonstrating that although the vascular resection group showed longer operative time and blood loss, there was no difference in overall morbidity or even in mortality. On the other hand, Castleberry et al. ${ }^{3}$ used data from the American College of Surgeons' national registry, involving 3582 patients subjected to pancreaticoduodenectomy from 2005 to 2009, of which 281 patients underwent vascular resection. The authors found higher morbimortality related to the group that underwent resection. A possible explanation for such discrepancy may be related to the known superiority of results observed in uni-institutional surgical series when comparing them with those from surveys involving large numbers of services with varied experience.

There was high morbidity in this series, and it was more related to the larger tumor sizes and surgery complexity than it was to the consequence of mesenteric ischemia or local technical complication from vascular reconstruction. This can be evidenced by the average operative time of 556 min, which was longer than that observed by the group in other published series of pancreaticoduodenectomies ${ }^{1}$. In fact, it was possible to correlate the vascular clamping as a causal factor for the development of pancreatic fistula and anastomotic bleeding in only one patient in the current study. This patient needed two venous reconstructions, since the primary suture of the vascular stumps showed tension and it led to immediate thrombosis at the 
anastomosis level. The problem was corrected by means of graft with polytetrafluoroethylene vascular prosthesis. As a consequence, clamping time was too long (100 min) and it turned the intestinal loops swollen and friable by venous stasis, thus contributing to the development of pancreatic fistula and gastrointestinal bleeding, both of grade $C$.

The oncologic benefit was another concern. Currently, there is great debate related to long-term survival of vascular resection in pancreatic cancer surgery. In reviewing the literature on the subject, Ramacciato et al. ${ }^{9}$ selected 12 studies that covered a total of 399 patients subjected to pancreaticoduodenectomy with associated MPA resection. The survival median ranged from 13-22 months, whereas the five-year survival rate ranged from 8.4 to $18 \%$. As a further finding of the study, 10 living patients (48\%) were found 10 years after the surgical procedure. The authors, based on their findings, recommended the MPA resection with vascular reconstruction, whenever feasible, in all patients who need it during pancreaticoduodenectomy.

Two recent case series publications involving more than 100 patients suggest inferior outcomes in pancreaticoduodenectomy associated with vascular resection when compared with pancreaticoduodenectomy as a single procedure 7,12 . This viewpoint is contrary to that advocated by the MD Anderson Hospital group who, 18 years ago, suggested that the MPA tumor invasion is not associated with any histological parameters of tumor aggressiveness and poor prognosis, but it is only a reflex of the tumor emergence near the MPA ${ }^{5}$.

The small number of patients with pancreatic adenocarcinoma in the current series prevents any valid conclusion about prognosis. However, according to this sample, one can suggest that most cases had advanced diseases with large tumors and lymph node impairment, which was consistent with the median survival of 15 months and a null survival rate at five years. It is noticed that the tumors that invade the MPA are, in general, advanced and such aspect should be discussed with the patient prior to their surgical indication. In this advanced disease scenario, neoadjuvant chemotherapy and radiotherapy are attractive possibilities that have been practiced in large centers ${ }^{4}$.

From this experience and based on the current literature, some important technical details are considered as important: 1) completely release the specimen prior to vascular resection allowing smaller clamping time for vascular reconstruction with little splanchnic congestion and assessing the tumor involvement in the superior mesenteric artery before resection - some of the various types of technical possibilities that address the superior mesenteric artery ("artery first approach") should be practiced $^{10}$; 2) the approximation of the vascular stumps is the best reconstruction technique since it is quick and allows suturing the veins with the same caliber; 3 ) the surgical team should be prepared for the different MPA reconstruction possibilities, since the length of the resected vein alone does not necessarily define whether stumps approximation will occur without tension. The splenic vein preservation may limit the approximation in isolated resections of the portal vein or inferior mesenteric vein ${ }^{11}$. It happened in one case, and required the use of a graft in order to correct intraoperative thrombosis.
CONCLUSION

The mesenteric-portal axis resection is a valid technical practice. It should be taken under consideration after contemplating not only the patients' clinical condition, the technical and the anatomical status of tumor infiltration in the mesenteric-portal axis, but also - and not least important -, considering the expected survival based on the patient's cancer prognosis.

\section{REFERENCES}

1. Amico EC, AlvesJR, JoãoSA, Guimarães PLFC, Barreto EJSS, Barreto Costa PRL, et al. Complicações após pancreatectomias: estudo prospectivo após as novas classificações GIEDFP e GIECP. ABCD Arq Bras Cir Dig 2013; 26(3): 213-218.

2. Bassi C, Dervenis C, Butturini G, Fingerhut A, Yeo C, Izbicki J, et al. International Study Group on Pancreatic Fistula Definition. Postoperative pancreatic fistula: an international study group (ISGPF) definition. Surgery 2005; 138(1):8-13.

3. Castleberry AW, White RR, De La Fuente SG, Clary BM, Blazer DG III, McCann RL, et al. The impact of vascular resection on early postoperative outcomes after pancreaticoduodenectomy: an analysis of the American College of Surgeons National Surgical Quality Improvement Program database. Ann Surg Oncol. 2012; 19(13):4068-77

4. Estrella JS, Rashid A, Fleming JB, Katz MH, Lee JE, Wolf RA, et al. Posttherapy pathologic stage and survival in patients with pancreatic ductal adenocarcinoma treated with neoadjuvant chemoradiation. Cancer. 2012; 118(1):268-77.

5. Fuhrman GM1, Leach SD, Staley CA, Cusack JC, Charnsangavej C, Cleary $K R$, et al. Rationale for en bloc vein resection in the treatment of pancreatic adenocarcinoma adherent to the superior mesentericportal vein confluence. Pancreatic Tumor Study Group. Ann Surg. 1996; 223(2):154-62

6. Hirono S, Kawai M, Tani M, Okada K, Miyazawa M, Shimizu A, et al. Indication for the use of an interposed graft during portal vein and/or superior mesenteric vein reconstruction in pancreatic resection based on perioperative outcomes. Langenbecks Arch Surg. 2014; 399(4):461-71

7. Kurihara C, Yoshimi F, Sasaki K, Nakao K, lijima T, Kawasaki H, et al. Impact of portal vein invasion and resection length in pancreatoduodenectomy on the survival rate of pancreatic head cancer. Hepatogastroenterology. 2013; 60(127):1759-65.

8. Moore GE, Sako Y, Thomas LB. Radical pancreatoduodenectomy with resection and reanastomosis of the superior mesenteric vein. Surgery. 1951; 30(3):550-3.

9. Ramacciato G, Mercantini P, Petrucciani N, Giaccaglia V, Nigri G, Ravaioli $M$, et al. Does portal-superior mesenteric vein invasion still indicate irresectability for pancreatic carcinoma? Ann Surg Oncol. 2009; 16(4):817-25.

10. Sanjay P, Takaori K, Govil S, Shrikhande SV, Windsor JA. 'Artery-first' approaches to pancreatoduodenectomy. Br J Surg. 2012; 99(8):1027-35

11. Tseng JF, Raut CP, Lee JE, Pisters PW, Vauthey JN, Abdalla EK, et al. Pancreaticoduodenectomy with vascular resection: margin status and survival duration. J Gastrointest Surg. 2004; 8(8):935-49.

12. Wang F, Gill AJ, Neale M, Puttaswamy V, Gananadha S, Pavlakis N, et al. Adverse tumor biology associated with mesenterico-portal vein resection influences survival in patients with pancreatic ductal adenocarcinoma. Ann Surg Oncol. 2014; 21(6):1937-47.

13. Wente MN, Bassi C, Dervenis C, Fingerhut A, Gouma DJ, Izbicki JR, et al. Delayed gastric emptying (DGE) after pancreatic surgery: A suggested definition by theInternational Study Group ofPancreatic Surgery(ISGPS). Surgery 2007; 142:761-768.

14. Wente MN, Veit JA, Bassi C, Dervenis C, Fingerhut A, Gouma DJ, et al. Postpancreatectomy hemorrhage (PPH) - An International Study Group of Pancreatic Surgery (ISGPS) definition. Surgery 2007; 142:20-25.

15. YuXZ, LiJ, Fu DL, DiY, Yang F, HaoSJ, etal. Benefitfrom synchronous portalsuperior mesenteric vein resection during pancreaticoduodenectomy for cancer: a meta-analysis. Eur J Surg Oncol. 2014; 40(4):371-8. 